\title{
Envelhecer em contexto prisional
}

\author{
Ageing in a prison environment
}

\section{Resumo}

O significativo aumento do número de pessoas idosas a nível mundial e em Portugal coloca aos nossos destinos coletivos novas preocupações e desafios. No âmbito desta investigação, definiu-se como objetivo a compreensão dos diferentes processos de envelhecimento dos reclusos considerados idosos, sendo analisados o quotidiano da população reclusa mais velha, o impacto dessa reclusão no seu processo de envelhecimento (nomeadamente na construção de estratégias de adaptação e reintegração) e suas perspectivas futuras de reinserção social. Este estudo, sustentado numa metodologia qualitativa, aplicou a análise de conteúdo a 25 entrevistas semidiretivas realizadas com indivíduos reclusos do sexo masculino com idade igual ou superior a 65 anos e que cumpriam pena de prisão em diferentes cadeias portuguesas que albergam homens. Conclui-se que, para os reclusos considerados idosos em contexto prisional, a percepção de envelhecer está ligada a sentimentos de conotação negativa, de inutilidade, de desespero e de perdas constantes. Essas pessoas investem, assim, todos os seus sentidos, capacidades intelectuais, sentimentos, ideias e estratégias adaptativas num processo de reformulação identitária, em que seu envelhecimento se associa a percepções de determinadas incapacidades que se evidenciam mais facilmente e se agravam em contexto prisional.

\section{Abstract}

The significant increase in the number of elderly worldwide and Portugal puts our collective destinies new concerns and challenges. Within this research, we defined the purpose to understand the different aging processes of inmates considered old and analyzed the daily lives of older inmates, the impact of imprisonment in the aging process (notably construction of adaptation strategies and reintegration) and its future prospects probation. This study supported a qualitative methodology, applied to the 25 semi-directive interviews content analysis performed with male inmates individuals aged over 65 years and serving sentences of imprisonment in different Portuguese
Cristina Sofia Lima dos Santos' Adriano Zilhão de Queirós Nogueira'
Palavras-chave:

Envelhecimento. Prisão. Quotidiano Institucional de Destituição. Adaptação. Carreira Moral.
Key words: Ageing. Prison. Institutional Quotidian of Destitution. Adaptation. Moral Career

\footnotetext{
Instituto Superior de Serviço Social do Porto, Mestrado em Gerontologia Social. Senhora da Hora, Porto, Portugal.
} 
chains harboring men. We conclude that, for prisoners considered elderly in the prison context, the perception of aging is linked to feelings of negative connotation of worthlessness, hopelessness and constant losses. These people invest, so all their senses, intellectual abilities, feelings, ideas and adaptive strategies in identity reformulation process, in which aging is associated with perceptions of certain disabilities that stand out more easily and worsen in the prison context.

\section{INTRODUÇÃO}

A sociedade portuguesa vive um acentuado processo de envelhecimento demográfico, resultante, essencialmente, da passagem rápida de um modelo de fecundidade e mortalidade elevados, para um modelo em que ambos os fenômenos atingem níveis particularmente baixos. Ou seja, o número de pessoas idosas cresce a um ritmo maior do que a natalidade. Por este motivo, o envelhecimento da população portuguesa tem se acentuado, quer na base da pirâmide etária, com a diminuição da população jovem, quer pelo topo, com o incremento da população idosa. ${ }^{1,2}$

O contexto prisional, constituindo um caso específico de concentração de pessoas numa instituição, pode caraterizar-se pela presença de sentimentos de frustração, ócio, desacreditação no futuro próximo, violência, ruptura de laços familiares e sociais, desenvolvimento de perturbações mentais, entre outros, que quando conjugados entre si, poderão prejudicar a qualidade de vida do seu público e, de certo modo, acelerar seu processo de envelhecimento. ${ }^{3}$

De fato, sob uma perspetiva sociológica, esse tipo de instituição - prisão - pode ser estudado à luz do conceito de Instituição Total, ${ }^{4}$ onde ocorrem experiências extremas, como nas prisões, hospitais, mosteiros/conventos, campos militares, navios, campos de concentração e colégios militares com internato. Esse conceito de instituição ${ }^{4}$ é exemplo de uma generalização formal que visa captar alguns aspetos formais da vida organizacional, suscetíveis de serem observados em organizações concretas, que desenvolvem atividades diversificadas.
Assim, a Instituição Total traduz-se por excelência num lugar de "residência e de trabalho onde um grande número de indivíduos, colocados na mesma situação, privados do exterior por um período relativamente longo, levam em conjunto uma vida reclusa, cujas atividades estão minuciosa e explicitamente reguladas". ${ }^{4}$ Por outras palavras, uma dada instituição assume um caráter totalitarista quando acaba por preencher, senão todas, a maioria das dimensões da vida de cada indivíduo que passa grande parte do seu tempo lá.

A instituição prisional assume-se como sendo fonte de destituição, pois seus internados não possuem qualquer tipo de privacidade. É usual a chegada de internados à instituição providos de uma cultura ilusória "derivada de um mundo em família - uma forma de vida e um conjunto de atividades aceites sem discussão até ao momento de admissão na instituição". ${ }^{4}$ A institucionalização do indivíduo irá implicar uma despersonalização do mesmo, despojando-o da sua personalidade anterior, modificando a imagem que esse possui de si próprio e dos outros, transmitindo-lhe um novo estatuto social, conformando-o assim, com seu novo papel. ${ }^{4}$

Se a pessoa passa toda a vida na instituição, esta assume-se como sendo "total" e isso se acentuará mediante uma imposição de horários, regras de trabalho, novas formas de comunicação, atribuição de estatutos e de papéis, que poderá contribuir "decisivamente para a construção e identidade de uma determinada realidade social". ${ }^{5}$ As instituições totais evidenciam um exercício coercivo do poder, isto é, um controle exercido sobretudo através de ameaças e sanções físicas e 
morais, personificadas no pessoal de vigilância e nos detidos, atuando entre si na conquista de privilégios internos. ${ }^{4}$

Uma instituição total assume-se, portanto, como uma mistura entre comunidade residencial e estrutura regulamentada, considerando o grau de internamento (frequência e intensidade de intercâmbios com o mundo externo) e a regulamentação, polos fundamentais de articulação do modelo, entendido como sendo um conjunto de normas que se aplicam num sistema social e que definem o que é legítimo e o que não o é, dentro desse sistema. ${ }^{6,7}$

O conceito de carreira permite, justamente, dar conta não só dessa experiência institucional, bem como do processo no qual o recluso se representa a si próprio e aos outros, reconstruindo um novo universo, progressivamente, adequado ao contexto da instituição prisional. A carreira moral, no seu "decurso de vida", pressupõe a vivência, por parte do indivíduo, de importantes etapas e conjuntos de acontecimentos que, decorrendo em momentos diferentes, contribuem decisivamente para o aprofundamento de determinada identidade. ${ }^{4}$

Contudo, a entrada de um indivíduo numa instituição com caraterísticas totalitárias simboliza uma ruptura com o meio ambiente material e social, no qual sua vida decorria. ${ }^{6}$ Dessa forma, o indivíduo é destituído de suas certezas e despojado da sua rede de relações sociais, parte integrante da sua identidade social. Acrescentase, ainda, que o período de institucionalização pode considerar-se como uma espécie de "reta final" da vida do indivíduo, sem expectativas de "horizonte social". ${ }^{6}$

O internamento prisional pode revelar-se, assim, como uma carreira ou processo progressivo de aprofundamento de determinada identidade - nesse caso, de recluso - na medida em que o indivíduo, ao longo do período de internamento, vivencia diferentes fases de adaptação à sua nova condição. Esse é necessariamente despojado do seu eu pré-institucional, adquirindo nova identidade, a de recluso, estando por isso submisso a toda uma dinâmica institucional estigmatizante. $^{4}$

O conceito de estigma foi igualmente importante para a compreensão dos processos de adaptação às instituições de caráter totalitário. Esse conceito refere-se a uma característica ou atributo que expõe um indivíduo ou uma categoria de indivíduos a fortes reações de descrédito por parte dos outros, pela atribuição de uma identidade severamente desvalorizada. Essa desvalorização simbólica provoca uma marcação de distância, um afastamento (segregação) e um tratamento penalizante ou negação de direitos (discriminação). ${ }^{8}$

Esse rótulo emerge do "cariz estigmatizante que a sociedade lhes apõe e/ou os internados assumem", próprio de todas as instituições de caráter totalitário.? Considera-se, ainda, a existência de uma característica inerente a todas as instituições totais - mais concretamente, o caráter estigmatizante. Esse tipo de instituição possui caráter estigmatizante, não só por a sociedade diferenciar os internados rotulando-os negativamente, mas também devido ao próprio internado assumir (negativamente, ou em casos de hiperconformismo, de forma positiva) sua diferença. ${ }^{9}$

O processo de mortificação do eu desenvolvido pelos reclusos tem também significativo impacto na identidade desses indivíduos, variando conforme o grau de vulnerabilidade de cada um induzido pela ordem institucional. Todo o processo de reclusão implica uma "desorganização" da personalidade do indivíduo, resultado de um enfraquecimento mental devido à limitação de horizontes e a uma infantilização devida ao despoletar no indivíduo de sentimentos de impotência e de inferioridade, no meio onde se encontra. Resultado de toda essa sequência de acontecimentos, o indivíduo tende a dissipar todo seu referencial pessoal anterior, para integrar um novo grupo de exclusão - o dos reclusos. $^{4}$ 
Também em todas as instituições totalitárias, a adoção de comportamentos adequados é encorajada por um eficaz sistema de privilégios que, em grande parte, fornece aos indivíduos a ossatura da sua nova personalidade e consagra sua ruptura com o mundo anterior. A instituição concede-lhes um conjunto de favores e recompensas em troca de sua submissão e colaboração. Assim sendo, as regras da casa são entendidas como sendo um conjunto relativamente claro e rígido, de ordens e proibições que informam os indivíduos acerca das exigências que lhe são impostas ao longo do seu percurso institucional. Contudo, paralelamente, verifica-se a existência de um sistema de pequenas recompensas que poderão ser obtidas em troca de obediência e respeito às normas vigentes. ${ }^{4}$ Dessa forma, denota-se que o sistema de privilégios/recompensas, bem como o processo de mortificação do eu, "constituem as condições a que o internado precisa adaptar-se". ${ }^{4}$

Noentanto, aointegraroambienteinstitucional, o indivíduo irá desenvolver diferentes formas de adaptação, consoante as diferentes fases da sua carreira moral, podendo adotar diferentes estratégias comportamentais, num mesmo tempo. $\mathrm{O}$ processo de adaptação à prisão consiste na forma de cumprimento da pena escolhida pelo sujeito, que sofre a influência de fatores variados. Esse processo assume diferentes contornos de indivíduo para indivíduo, sendo determinante na aplicação de medidas de flexibilização da pena e nos planos de tratamento prisional. Assim, no processo de adaptação institucional, o recluso desenvolve um mecanismo que o permite adaptarse à nova realidade que dependerá das condutas criminais e sociais, da experiência prisional, bem como da sua receptividade às diversas mecânicas institucionais. ${ }^{4}$

Nessa investigação pretendeu-se, assim, compreender os diferentes processos de envelhecimento dos reclusos considerados idosos, sendo analisado o quotidiano da população reclusa mais velha, o impacto dessa reclusão no seu processo de envelhecimento (nomeadamente na construção de estratégias de adaptação e reintegração) e suas perspectivas futuras de reinserção social.

\section{METODOLOGIA}

A análise dos significados, a descoberta dos sentidos, as razões dos atos, a relação entre o sujeito e seu mundo são alvos da análise qualitativa. Neste estudo, por meio do recurso a um paradigma interpretativo da realidade, contemplando procedimentos qualitativos de coleta de dados, como a entrevista, e procedimentos qualitativos de tratamento de dados, como a técnica de análise de conteúdo, optou-se pela utilização de entrevistas semidiretivas como instrumento privilegiado de penetração no domínio representacional de cada indivíduo. A entrevista constitui uma técnica de interação objetiva e contextualizada entre o entrevistado e o entrevistador.

As questões colocadas na entrevista centramse num "ponto de vista pessoal" e personalizado, até mesmo "intimista", enfatizando a experiência pessoal de cada um. ${ }^{10}$ Essas questões se inspiram numa das investigações pioneiras em torno do envelhecimento prisional. ${ }^{11}$

Ghiglione \& Matalon ${ }^{12}$ concluem que, após um número de 20 a 30 entrevistas, não surgem novas informações: "20 entrevistas serão, em geral, mais do que suficientes; as seguintes apenas confirmarão o que tivermos obtido com a análise das primeiras". Foram exatamente 25 as entrevistas aplicadas a indivíduos do sexo masculino, com idade igual ou superior a 65 anos, cumprindo pena de prisão em Portugal, nomeadamente, nos Estabelecimentos Prisionais Especiais de Vale do Sousa e Santa Cruz do Bispo e Regional de Paços de Ferreira, após a aprovação do estudo pela Direção Geral dos Serviços Prisionais (ofício no 229/DSPRE, de 06/12/2012). Em cada estabelecimento prisional, os indivíduos entrevistados foram indicados pelo diretor local, que forneceu uma listagem de 
reclusos inseridos no critério etário mencionado. O período de coleta de dados decorreu entre 03 e 16 de janeiro de 2013.

A partir da análise das listagens fornecidas, foram selecionados os 25 participantes. Contudo, alguns dos reclusos mais velhos não puderam ser entrevistados, por se encontrarem internados na clínica de saúde mental, designada de DIP (Declarados Inimputáveis Perigosos) do Estabelecimento Prisional Especial de Santa Cruz do Bispo. Do grupo selecionado, apenas um recluso se recusou a responder, alegando não dispor de nenhum tipo de "benefício" judicial mediante sua colaboração na investigação, pelo que para o fazer teria que ser recompensado. Por esse motivo, foi necessário selecionar outro recluso que reunisse os critérios do estudo para completar o total de 25 entrevistados.

Em cada entrevista realizada, estabeleceuse um "contrato de comunicação", mediante a apresentação do entrevistador, explicação da modalidade de coleta de informação, dos objetivos do estudo e assinatura da declaração de consentimento informado garantindo $\mathrm{O}$ anonimato. ${ }^{10}$ Todos os inquiridos assinaram o consentimento informado.

Para o tratamento dos dados recolhidos através da aplicação das entrevistas, recorreuse à técnica de análise de conteúdo para obter uma leitura mais aprofundada das informações disponibilizadas pelos entrevistados. Esta técnica permitiu transformar a comunicação e os registos verbais dos atores institucionais em elementos dotados de revelação e significado da dimensão cognitiva do emissor. ${ }^{13}$

A análise de conteúdo das entrevistas semidiretivas aplicadas no âmbito do estudo obedeceu a três importantes momentos: a préanálise, a exploração do material eo tratamento dos resultados obtidos com respectiva interpretação. A pré-análise requereu a organização de todo o material disponível, seguindo-se uma seleção do conteúdo das entrevistas a analisar, mediante uma primeira leitura do material recolhido. De seguida, delimitaram-se as unidades de registo, em harmonia com os objetos de estudo delineados e respectiva problemática teórica. Relativamente à escolha das regras de contagem, optou-se pela frequência simples, em que todas as unidades de registo assumem a mesma importância. ${ }^{14}$

A exploração do material operacionalizou-se através da codificação dos dados, organizados em 14 diferentes temas, através dos quais se definiram 34 categorias e 11 subcategorias de análise. A unidade de enumeração condutora desse processo pode ser geométrica ou aritmética. ${ }^{15}$ A primeira, sobre a qual incidiu a escolha desse projeto, possibilita a contagem do "número de vezes que aparece um determinado conteúdo".12

Trata-se, portanto, de uma análise de conteúdo de tipo temático, na medida em que se esforça por aceder às interpretações subjetivas dos entrevistados sobre o fenômeno do envelhecimento num contexto privativo de liberdade, através da exploração das unidades de registro selecionadas, utilizando a "regra" da frase-ideia. ${ }^{13}$ Partiu-se das unidades de registro para a extração de categorias e subcategorias, registando-se a frequência simples e enumerandoas geometricamente. O tratamento e interpretação dos resultados obtidos junto aos reclusos entrevistados, no quadro teórico desenvolvido, possibilitou uma leitura da realidade investigada, à luz dos objetivos modeladores de todo o estudo.

Tendo sido facultada a consulta dos processos individuais dos reclusos previamente à aplicação das entrevistas, também se recorreu à técnica de análise documental, que procura identificar informações factuais nos documentos. ${ }^{16}$ Enfatizou-se, portanto, a análise de informações respeitantes ao tipo de crime(s) cometido(s) e à trajetória biográfica dos indivíduos, pois, devido à especificidade dessas temáticas, em situação de entrevista essa informação poderia não fluir espontaneamente no discurso do entrevistado, podendo despoletar situações constrangedoras. 
O universo entrevistado foi então composto por 25 indivíduos do sexo masculino, com idade igual ou superior a 65 anos de idade, que cumpriam pena privativa de liberdade em diferentes estabelecimentos prisionais portugueses que albergam homens. Os dados analisados caraterizadores desse universo são: escalão etário, tipo de reclusos, habilitações literárias, tipo de crime praticado e duração das penas privativas de liberdade.

\section{RESULTADOS E DISCUSSÃO}

O tratamento e interpretação dos resultados permitem, desde logo, verificar maior prevalência do número de indivíduos penalizados por crime de homicídio qualificado, e num total de 25 entrevistados, dez praticaram o referido tipo de crime. Desses dez casos analisados, ressalvase que três homicídios resultaram na morte do cônjuge/companheira do entrevistado. Destacase, ainda, o caso de um indivíduo condenado a pena máxima de prisão em Portugal (25 anos) acusado de 35 crimes de homicídio, dos quais 13 consumados e 22 na forma tentada. O crime de tráfico de estupefacientes é o segundo tipo de crime com maior incidência, sendo quatro os indivíduos acusados. Os crimes de abuso sexual de menores, rapto e lenocínio também se evidenciaram no universo pesquisado, sendo um total de dois indivíduos acusados por cada tipo de crime referido.

Quanto à duração das penas privativas de liberdade (em anos), verifica-se que a pena mais curta tem duração de dois anos (aplicada apenas a um indivíduo), e a pena mais longa respeita os 25 anos de prisão, tendo sido aplicada a dois dos entrevistados. Nesses casos em particular, a decisão pela pena máxima de prisão em Portugal deveu-se ao tipo de crime praticado, nomeadamente "abuso sexual de menores" e "homicídio qualificado". A média das penas aplicadas situa-se nos cinco anos de duração e abrange apenas quatro indivíduos.

O tratamento e interpretação dos resultados estruturam-se também em 14 temas fundamentais, através dos quais emergem as respectivas categorias e subcategorias de análise e cuja frequência de resposta se assinala entre parênteses.

O primeiro tema, "significado do envelhecimento e de velbice na perspectiva do sujeito", evidencia quatro categorias: a "relação do envelhecer com a doença e incapacidade" (12), que acentua a tendência de associação, pelos entrevistados, do envelhecimento com o surgimento de determinadas doenças e incapacidades. A "percepção do envelhecimento e da velhice como sequência do curso de vida" (7) subentende essas temáticas como sendo uma sequência natural do curso de vida dos indivíduos. O surgimento de "sentimentos negativos" (3) devese a considerar o envelhecimento e a velhice como fase última da vida humana, repleta de sofrimento, à qual não manifestam vontade em "chegar": "envelhecimento é perda de força e de vontade, desistir do mundo..., a velbice é o último episódio da vida do ser bumano" (2 $2^{\mathrm{a}}$ entrevista). Verifica-se ainda uma "resistência ao envelhecimento" (3) naqueles que alegaram não se sentir envelhecendo por ainda se sentirem jovens, travando uma luta constante contra o envelhecimento.

$\mathrm{O}$ tema "significado de ingresso na prisão" apresenta três categorias de análise, que reúnem interpretações subjetivas referentes à institucionalização como tendo sido um "acontecimento traumatizante" (12). Seguidamente, surge o "quotidiano institucional rotineiro como fator de stress" (10), que denuncia a existência de rígidos horários e normas, produtoras de um quotidiano de caráter extremamente rotineiro e não aliciante. Por último, surge o "conformismo" (3) daqueles que aceitaram a sanção aplicada sem relutância.

\section{A temática "entrada e adaptação à prisão"} analisa o momento de entrada e o respectivo processo faseado de adaptação à instituição prisional. Verifica-se uma "importância da prática laboral e formativa como estratégias de reclusão" (13), sendo a forma eleita pela maioria dos reclusos para melhor se adaptarem ao mecanismo prisional e "mais facilmente" alcançarem o fim da pena prevista. A "tendência de isolamento 
por precaução de segurança pessoal" (7) circunscreve aqueles que tendem a estabelecer poucos contactos com terceiros, mantendo reduzida rede de sociabilidades institucionais. Além de ser tido como "difícil" o relacionamento interpessoal prisional, alguns dos indivíduos também não se identificavam com as restantes faixas etárias, tendendo a se isolar. A "necessidade de integração institucional" (5) circunscreve os que manifestaram vontade de se integrar na dinâmica institucional, através do convívio. Esses casos resultam da aceitação e interiorização da pena aplicada, surgindo a necessidade de cumprir a sentença da "melhor" forma possível: "ia tomar um cafeaito de vez em quando para me adaptar ao ambiente" ( $5^{a}$ entrevista).

O tema "condições objetivas e subjetivas de vida anteriores à reclusão" uma análise por parte dos entrevistados relativamente a sua situação econômica e de saúde, prévios à entrada na instituição prisional. A primeira categoria, "situação econômica", subdivide-se em duas subcategorias, "stável" (22) e "instável" (3). Assim, a generalidade de entrevistados confirma uma situação econômica pré-institucional pautada por índices de estabilidade, pelo que apenas três entrevistados referem ter vivido períodos de elevada instabilidade econômica.

A categoria "estado de saúde" divide-se em duas subcategorias: "estável" (15) e "débil" (10). A generalidade inquirida carateriza o próprio estado de saúde, pré-institucional, como estável "a saúde lá fora era boa" ( $8^{\mathrm{a}}$ entrevista). Os restantes confirmaram um estado clínico debilitado " $j a ́$ sofria do coração, já tinha sido operado" ( $2^{\mathrm{a}}$ entrevista).

A temática "condições objetivas e subjetivas de vida posteriores à reclusão" pretende que os entrevistados analisem determinados aspectos (conjuntura econômica, saúde e padrões culturais) que sofreram alterações posteriores à institucionalização, emergindo, assim, três categorias. A "situação econômica", decomposta nas subcategorias "instável" (14), referente aos que afirmaram vivenciar um período de instabilidade econômica, agravado essencialmente desde o início de cumprimento de pena: "roubaram-me tudo, depois de já estar preso, assinei uma procuração e tiraramme tudo" ( $8^{\text {a }}$ entrevista). Alguns entrevistados tendem a comparar sua situação econômica atual com a situação passada, evidenciando sinais de ter sido melhor que a atual. E "estável” (11) no caso dos que se reformaram após a institucionalização, podendo beneficiar de uma prestação mensal capaz de suprir determinadas despesas.

A categoria "estado de saúde" subdivide-se em duas subcategorias: "débil" (19), referente aos reclusos que afirmaram ter assistido a um agravamento do seu estado de saúde após a institucionalização: "a minha saúde está pior, já fui operado à próstata" ( $8^{a}$ entrevista). E o estado "inalterado" (6), referente aos que afirmaram não ter "sentido" qualquer alteração: "a saúde não melhorou porque aqui dentro ninguém melhora, mas também não agravou, apesar de aqui haverem hepatites, sidas, todos os problemas, em termos bigiênicos" (1 ${ }^{\text {a }}$ entrevista).

A categoria "indices culturais" divide-se em três subcategorias reveladoras de casos tidos como "inalterados" (10), de "melhoria" (9) e de "agravamento" (6). Ou seja, a maioria dos entrevistados afirmou não ter verificado qualquer alteração cultural por se encontrar privada de "tudo", podendo isso constituir um obstáculo ao desenvolvimento cultural e intelectual. Por sua vez, nove entrevistados acusaram ter sentido uma "melhoria" em seus padrões culturais, devido à frequência escolar e profissional prisional. Por último, seis entrevistados denunciaram um "agravamento" cultural desde que institucionalizados.

O tema "estrutura identitária pós-reclusão" propõe aos entrevistados uma introspecção reflexiva sobre o seu "eu", suscetível de modificação, mediante a privação de liberdade e respectivo processo de despersonalização e de mortificação do eu a que estão sujeitos. ${ }^{4}$ Surgem duas categorias de análise: a "não alteração do eu"(15), referente aos que confirmaram não ter sentido qualquer mudança em si mesmos mediante a institucionalização. A "metamorfose do eu" (10), por sua vez, situa aqueles que confirmaram ter sofrido modificações de índole psicossocial devido 
ao caráter totalitário da instituição prisional que, através do seu forte poder normativo e coercivo, é capaz de despojar os reclusos da sua personalidade anterior, "obrigando-os" a refletir sobre seus atos, transformando-os.

A temática "representação social $d a$ população reclusa anterior à reclusão" analisa as representações que os entrevistados possuíam sobre a população reclusa prévia a sua própria privação da liberdade e qual a imagem que, sobre essa mesma população, é socialmente construída. Delinearam-se duas categorias de análise: o "estigma" (20), que os entrevistados consideraram estar presente nas suas próprias representações acerca da prisão e respectivos reclusos, considerando que o restante da sociedade possui a mesma "representação" da população prisional. E a "percep̧cão realista" (5) daqueles que confirmaram ter "sempre" tido acerca do contexto prisional.

O tema "representação atual da prisão e da população prisional” evidencia duas categorias: a "diferenciação entre reclusos" (13), na qual é perceptível a tendência dos entrevistados que necessitavam se distinguir dos restantes reclusos mediante o tipo de crime praticado. $\mathrm{O}$ delito cometido é interpretado, por alguns, como tendo conotação menos grave, comparativamente com os restantes reclusos que praticaram crimes "mais graves". A categoria "descrença na capacidade regeneradora da prisão" (12) evidencia-se pelos que desacreditavam na eficácia dos objetivos que a prisão se propõe a conseguir, crendo apenas depender da força de vontade de cada um.

A temática "representação da população prisional acerca da idade" apresenta duas categorias: a "diferenciação etária nas práticas quotidianas" (15), que confirma a existência de uma distinção entre os diferentes grupos etários, perceptível nas formas de ocupação dos tempos livres. Se os reclusos mais novos optam por práticas desportivas intensas (futebol e basquetebol), os mais velhos preferem jogos tradicionais (cartas e damas) tidos como sendo mais "calmos". Por último, a categoria "indiferenciação etária" (10) engloba aqueles que afirmaram não haver distinção entre reclusos em função da idade. O tema "relacionamentos extramuros" foca nos contatos estabelecidos entre reclusos e respectivos familiares e amigos, conseguidos mediante diferentes formas (cartas escritas, chamadas telefônicas, visitas à prisão e/ ou saídas precárias dos reclusos). Surge assim uma única categoria de análise, "importância do apoio e dos contatos com familiares e amigos" (25), que atribui fulcral importância a esses contatos, constituindo importante incentivo a uma melhor adaptação institucional e suprimento da pena aplicada (o mais emocionalmente estável possível).

$\mathrm{Na}$ temática "trajetória prisional” dos reclusos, todo o universo entrevistado apresentou respostas unânimes que evidenciam a existência de um "percurso sem sanções disciplinares e linear": "cumpri sempre estritamente as regras do estabelecimento" ( $9^{a}$ entrevista); "um percurso exemplar, estou detido desde 17 de agosto de 2005 e até hoje não tenho uma chamada de atenção, sem reparos" ( $1^{\mathrm{a}}$ entrevista). A tendência de esses entrevistados evidenciarem, desde o ingresso institucional à atualidade, um percurso linear, conforme aos padrões institucionais, justifica-se pela vontade manifestada de sair em liberdade antes do fim da pena, podendo ainda usufruir de saídas precárias, entre outras "recompensas" institucionais.

O tema "perspetivas da trajetória de vida sem reclusão" pressupõe a idealização dos cursos de vida dos entrevistados, caso não tivessem sido presos, edificando-se duas categorias: a existência de uma "perspectiva positiva" (22), referente aos que afirmaram ter dado continuidade a determinadas atividades ocupacionais e a relacionamentos afetivos, interrompidos pela privação da liberdade. Verifica-se também uma "incapacidade de idealização" (3) por parte dos restantes entrevistados: "não sei, não sei se estava vivo, se estava morto. A vida é assim mesmo" (14a entrevista).

$\mathrm{Na}$ temática "trajetória de vida após a reclusão”, evidenciam-se quatro categorias ditadoras dos planos futuros de vida dos entrevistados: a necessidade de "(re)estabelecer 
laços afetivos" (9) numa ótica de (re)aproximação familiar e de procura de "companhia" na "última" etapa da vida. A vontade de "retoma da prática laboral" (7), como recomeço de uma nova etapa da vida, o mais integrada possível np nível socioprofissional. Surgem também situações de "ausência de planificações de vida futuras" (6) por indivíduos que desacreditam na possibilidade de sobreviver até ao final da pena. Caso isso aconteça, creem estar demasiado incapacitados para traçar objetivos de vida, tendo por isso, perdido a esperança. E apenas três indivíduos manifestaram vontade de "transição para a reforma" como prioridade após saída em liberdade, para "garante" da sua subsistência.

A última temática, "motivos da prática do crime e respectiva interpretação", pressupõe uma interpretação do(s) motivo(s) originadores da prática criminal, traçando-se três categorias de análise: "arrependimento e assunção da culpa" (10), que engloba discursos reveladores de arrependimento face ao delito praticado. Esses indivíduos, apesar de interpretarem o período de reclusão como sendo "muito" custoso, encaram a pena aplicada como um castigo justo face ao ato praticado. A tendência de "vitimiz̧ação porparte de outrem" (10), por entrevistados que tendem a canalizar a culpa do delito praticado em pessoas e/ou circunstâncias que lhes são externas e "impossíveis" de controlar (traições, entre outros). E por último, a "neutralização da culpa através do uso de substâncias" (5), daqueles que, no momento da prática criminal, se encontravam sob o efeito de substâncias de índole medicamentosa/alcoólica. O consumo de substâncias alcoólicas, neste caso em particular, influencia a prática criminal nas pessoas idosas. ${ }^{17}$

As limitações do estudo são aquelas próprias do método de estudo de caso que, por suas caraterísticas metodológicas, impossibilitam a generalização de conclusões, não permitindo, por isso, sustentar que em todas as situações do mesmo tipo as conclusões seriam idênticas. De fato, o caráter aprofundado desta investigação apenas permite apresentar, sustentadamente, conclusões para o caso em estudo.

\section{CONCLUSÃO}

Nas últimas duas décadas, o aumento progressivo do número de indivíduos de idade avançada em situação de privação da liberdade despertou a curiosidade e o interesse das fontes literárias internacionais (de áreas como a saúde pública, a administração da justiça e estudos prisionais). Nessa ótica, a reintegração social dos cidadãos reclusos, nomeadamente os de idade avançada, integra-se no conjunto dos desafios multidisciplinares aos quais as sociedades contemporâneas se esforçam por responder.

A pertinência da escolha dessa temática deve-se, também, à exiguidade de estudos que articulem o binômio "envelhecimento e prisão", nomeadamente no caso português. Assim, apesar de no início da pesquisa bibliográfica se ter verificado uma imensidade de artigos, estudos e investigações em torno do contexto prisional, bem como do processo de envelhecimento, raros foram os dados encontrados que relacionassem ambas as temáticas.

A longevidade acarreta consigo a necessidade constante de adaptação a perdas, ocorridas ao longo do ciclo de vida do indivíduo. O fato de o indivíduo viver "mais tempo", assistindo à "partida" de seus entes mais próximos, suscita a reconstituição de vínculos sociais e a procura de novas formas de ocupação quotidiana, muitas vezes desprovida de suporte emocional.

Assim, em contexto prisional, o indivíduo considerado idoso sujeita-se a uma nova aprendizagem de convívio com indivíduos na mesma condição que lhe são totalmente desconhecidos, após um percurso de vida marcado pelo convívio com quem mantinha laços afetivos, tendo também que descuidar de seu estilo de vida pessoal e quotidiano para se adaptar a uma nova realidade. Por isso, nesse contexto, o recluso irá reconstituir seu quotidiano, empenhando todos seus sentidos, capacidades intelectuais, sentimentos, ideias e estratégias adaptativas. 
O tempo no qual o indivíduo se encontra preso é o mesmo tempo em que se encontra envelhecendo, pelo que esse envelhecer geralmente surge "travestido com uma roupagem diferente da usada na vida das pessoas livres. Para o preso, a contagem do tempo é regressiva: as horas, os minutos, os segundos são subtraídos da sua existência". ${ }^{3}$ Em contexto prisional verifica-se, ainda, acentuada diversidade etária entre reclusos. Esta convergência de diferentes escalões etários num mesmo espaço provoca maior exposição dos reclusos mais velhos a fatores causadores de estresse.

Esses indivíduos idosos, privados de liberdade e em ruptura com seu anterior estilo de vida, aprofundam, por isso, diferentes formas e estratégias de sobrevivência, nomeadamente através da adoção de comportamentos inadequados às normas institucionais ou através da submissão total a essas normas. As pessoas idosas em contexto prisional investem, assim, todos os seus sentidos, capacidades intelectuais, sentimentos, ideias e estratégias adaptativas numa "reformulação" profunda da sua identidade e de seus papéis, colocando assim, o desafio da sua reintegração social no conjunto de preocupações das sociedades contemporâneas desenvolvidas.

A temática da reinserção social dos reclusos considerados idosos surge como pertinente em investigações futuras, na medida em que esse processo se depara com uma ausência de enquadramento de medidas políticas vocacionadas para esse problema emergente nas sociedades contemporâneas.

\section{REFERÊNCIAS}

1. Ribeiro O, Paúl C, coordenadores. Manual de Envelhecimento Ativo. Lisboa: Lidel; 2011.

2. Organizações das Nações Unidas. Segunda Assembleia Mundial sobre Envelhecimento. Portugal: Centro de Informação das Nações Unidas em Portugal; 2002.

3. Suelma I. À espera da liberdade: um estudo sobre o envelhecimento prisional [dissertação]. São Paulo: PUC; 2003.

4. Goffman E. Manicômios, prisões e conventos. São Paulo: Perspectiva; 1961. p.11-59.

5. Gonçalves R. A adaptação à prisão: um processo vivido e observado. Lisboa: Direção-Geral dos Serviços Prisionais; 1993.

6. Barenys M. Residencias de ancianos: análisis sociológico. Barcelona: Fundación Caixa de Pensions; 1990.

7. Mendras H. Elements de sociologie. Paris: A. Colin; 1979.

8. Goffman E. Stigmate. Les usages sociausx des handicaps. Paris: Éditions Minuit; 1975.

9. Medeiros C, Coelho M, Gersão E, Moreira J, Cunha M. Do desvio à instituição total: subcultura, estigma, trajetos. Lisboa: Gabinete de Estudos Jurídico-Sociais do Centro de Estudos Judiciários; 1991.

10. Foddy W. Como perguntar : teoria e prática da construção de perguntas em entrevistas e questionários. Oeiras: Celta Editora; 1996. p. 23-91.

11. Kozlov E. Aging While incarcerated: a qualitative study of geriatric Prisoners in America. Conneticut: Wesleyan University; 2008.

12. Ghiglione R, Matalon B. O inquérito: teoria e prática. Oeiras: Celta; 1997. p. 54-92.

13. Quivy R, Campenhoudt L. Manual de investigação em ciências sociais. Lisboa: Gradiva; 1995.

14. Bardin L. Análise de conteúdo. Lisboa: Edições 70; 1977.

15. Vala J. A análise de conteúdo. In: Silva A, Pinto J, organizadores. Metodologia das Ciências Sociais. Porto: Afrontamento; 2003. p.101-28.

16. Lüdke M, André M. Pesquisa em educação: abordagens qualitativas. São Paulo: EPU; 1986.

17. Costa J. O idoso e o crime: prevenção e segurança. Lisboa: Edições Colibri; 2007. 